\title{
Graduate views on access to higher education: Is it really a case of pulling up the ladder?
}

\author{
Rob Webb ${ }^{1}$, Duncan Watson ${ }^{2}$, Steve Cook $^{3}$ and Fabio Arico ${ }^{4}$
}

\begin{abstract}
Using as a starting point the recent work of Mountford-Zimdars, Jones, Sullivan and Heath (2013), we analyse attitudes towards expanding HE opportunities in the UK. We propose that the approach of Mountford-Zimdars et al. is flawed not only in its adoption of a multivariate logistic regression but in its interpretation of results. We make a number of adaptations, chief among them the use of an ordered probit approach and the addition of a time dimension to test for changes in attitudes between 2000 and 2010. We find attitudes towards HE expansion have intensified during the decade 2000-2010, but we uncover no evidence that this is due to graduates wanting to 'pull up the ladder', as suggested by Mountford-Zimdars et al. We argue that evidence of a widespread desire to reduce access to HE can most likely be explained by social congestion theory, internal institutional disaffection and rising tuition fees.
\end{abstract}

Keywords: Higher Education; Expansion; Widening Access; Attitudes; Ordered Probit

${ }^{1}$ Corresponding Author: Division of Industrial Economics and Finance, Nottingham University Business School, University of Nottingham, Jubilee Campus, Wollaton Road, NG8 1BB (robert.webb@nottingham.ac.uk); ${ }^{2}$ School of Economics, University of East Anglia, Norwich Research Park, Norwich, NR4 7TJ (duncan.watson@uea.ac.uk); ${ }^{3}$ Swansea University, Singleton Park’ Swansea, SA2 8PP (s.cook@swansea.ac.uk); ${ }^{4}$ School of Economics, University of East Anglia, Norwich Research Park, Norwich, NR4 7TJ (f.arico@uea.ac.uk) 


\section{Introduction}

It has become largely accepted in recent decades that widening access to higher education (HE) delivers positive benefits to individuals and society. Agreement on this general point has emerged in spite of bitter discord over more specific areas of policy. The strength of the apparent consensus became especially evident in 1997, when the new Labour government fully endorsed the Dearing Report's recommendations to increase capacity and expand opportunities in HE.

The resulting government-backed initiative, AimHigher, set out to channel more students from minority groups and lower socio-economic backgrounds into HE. The coalition government scrapped the scheme in 2010, but the decision was rooted in concerns over approach rather than any misgivings about underlying ethos. A belief in broadening access has remained absolutely central to the policies and initiatives that have followed, with the National Scholarship scheme that replaced AimHigher enjoying similar levels of funding and the Social Mobility Strategy unveiled by the Deputy Prime Minister in 2011 retaining education as a key driver (Cabinet Office 2011).

Commentators have now started to challenge the notion that this enthusiasm for providing more opportunities in HE exists across society. Gorard (2013) and Mountford-Zimdars, Jones, Sullivan and Heath (2013) have been especially notable in casting doubt on the contention. By examining the British Social Attitudes (BSA) survey, Mountford-Zimdars et al. unearthed thought-provoking evidence that graduates in particular might oppose the continued expansion of access to HE.

In the first part of their paper Mountford-Zimdars et al. examined the evolving emphasis and semantics of questions regarding HE in Britain. They then considered the personal socioeconomic characteristics of respondents to the following question:

Do you feel that opportunities for young people in Britain to go on to higher education - to a university or college - should be increased or reduced, or are they at about the right level now?

Using a multinomial logit with 2010 data, Mountford-Zimdars et al analysed the answers of individuals who agreed that opportunities should be 'increased', were 'about right' or should be 'reduced' (Mountford-Zimdars et al. 2013, page 804). They found 'graduates were both less

likely to support an increase in opportunities and more likely to support a reduction in opportunities' (page 804). Although this result was not fully investigated, Mountford-Zimdars 
et al remarked in their closing comments that graduates are rational economic agents who are 'in favour of pulling up the ladder behind them and decreasing opportunities' (page 809).

The current paper revisits these findings, using Mountford-Zimdars et al. as a foundation on which to examine attitudes towards access to $\mathrm{HE}$ and the social characteristics of respondents. Focusing on the hypothesis that graduates are in favour of 'pulling up the ladder', we propose using an alternative and more robust methodological approach that allows a deeper investigation into the intensity of opinion regarding attitudes towards access to HE. We also develop the analysis in a number of different ways in an attempt to tease out clarity and to further examine the robustness of our own results and those of Mountford-Zimdars et al.

Firstly, we extend the dataset to include the years 2000, 2005 and 2010 of the BSA survey. We thus cover a period that witnessed participation in HE increase by more than 15 per cent. Expanding the period under scrutiny allows for a more complete analysis in a time of change and also permits a cross-section investigation of the percentage of graduates in the sample and an examination of regional data. Secondly, we delve deeper into the 2010 dataset, using additional perception variables to break down graduates into types. Overall, our approach allows for a more thorough inquiry into attitudes towards widening access to HE.

In the following sections we begin by examining the debate surrounding the expansion of access to HE. We then introduce our methodological approach in more detail. Finally, we reveal and interpret our results.

\section{'Today everybody has a degree’: participation, parity and perceptions}

Are some still more equal than others?

Over the past half-century government education policy has clearly focused on increasing participation and widening access for underrepresented groups. As Diamond has remarked, HE has thus 'turned from a privilege available to an elite few into a mass expectation' (Diamond in TLRP 2008 page 2). Yet the outcomes of these efforts, on balance, have been characterised by both conspicuous progress and worrying inertia.

The road to transformation began with the passing of the 1944 Education Act, which had at its heart a firm belief in equality of educational opportunity. This conviction formed the foundation of further policies that continued to nudge HE towards the twin goals of expansion and addressing the underrepresentation of certain societal groups - an approach that provided 
the basis of the 1963 Robbins Report on Higher Education, which recommended that HE should be available to 'all those who are qualified by ability and attainment' (Robbins 1963).

Although manifest, change remained evolutionary rather than revolutionary for more than 40 years. It was not until the late 1980s that the foundations were laid for what we now refer to as mass HE. The 1988 Education Reform Act widened the traditional routes from a focus on 'A' levels to vocational qualifications and access courses for older students, as well as allowing universities more flexibility in admitting students they believed would benefit. In 1992 the Further and Higher Education Act heralded the beginning of mass HE participation in earnest by granting university status to polytechnics - a move that saw participation rates increase from 19.3 per cent in 1990 to 33 per cent in 2000 (compared to 3.4 per cent in 1950 and 8.4 per cent in 1970 - see Bolton 2012).

Further growth continued before and after the dawn of the new millennium and became synonymous, at least in government eyes, with wider access, equality of opportunity and a more equitable society. To this end, HE received a significant push when the incoming Labour government of 1997 accepted the recommendations of the Dearing Report (1997). HE participation rates steadily rose towards a target of 50 per cent before plateauing in the latter half of the 2000s. By the academic year 2011/12 - a year after Labour had lost power participation rates had reached 49 per cent; they had fallen back to 43 per cent by 2013, partially as a consequence of the new coalition government's decision to raise tuition fees.

Many of the numbers speak for themselves. In 2000, for example, more than 240,000 students graduated. In 2012, for the first time, nearly 300,000 students enrolled at UK universities (Department for Business, Innovation and Skills 2014). There is also clear evidence, regarding actual numbers, that female students have more than gained parity with their male counterparts. For example, by the turn of the millennium close to 55 per cent of those undertaking a first degree were women, compared to less than 30 per cent at the beginning of the twentieth century (see Bolton 2012 and Universities UK 2012 and note that male/female inequality may persist in many other more subtle forms).

The data on participation rates by socio-economic class, however, are not so encouraging. While there is no doubt that more students from lower socio-economic classes (in absolute terms) were participating in HE by the turn of the millennium, as a proportion of the whole 
student body, students from social classes IIIm-V - which include those from families from manual occupational backgrounds - were still disadvantaged. As Bolton has observed:

the social make-up of those at university... changed little and, although the gap in participation has closed (on some measures), participation rates of classes IIIm-V in 1995 were still below those of classes I-IIIn in 1950. (Bolton 2010, page 8)

Alongside undeniable progress, then, there has been an unwelcome (and frequently unacknowledged) element of stasis. More than five decades of pro-HE policies have seen the relative participation of disaggregated socio-economic groups remain remarkably stable. HE is still dominated by the higher social-economic groups, and intergenerational social mobility remains limited. For all the well-intentioned efforts of the past half-century, inequalities persist; and as Gorard and Smith have stated: 'In so far as it is possible for there to be facts in social policy, these inequalities are fact.' (Gorard and Smith 2006, page 7)

\section{Expectation versus reality}

The arguments for the expansion and widening of access to HE seem to have a clear logical appeal. They are based around the perceived or expected benefits to individuals (e.g. prosperity) and society (e.g. enhancing the domestic economy and global economic competitiveness - see, for example, Department for Education and Skills 2006). As Robbins remarked in 1963: 'The good society desires equality of opportunity for its citizens.' Some have argued that HE has elements of both a public and a private good, in that it can benefit all in society while also benefiting the individual, is rationed and is (or can be) costly (see World Bank 1994, Altbach 1999, Walker 2010 and East, Stokes and Walker 2014).

The view of $\mathrm{HE}$ as a private good is rooted in evidence regarding the future earning power of graduates. There has emerged a conventional wisdom that all individuals, regardless of background, can personally benefit from undertaking HE. Work in the area of earning power of graduates is well established and seductive. Chesters and Watson (2013), for example, suggest that those individuals who graduate with a degree will be able to demand - and, moreover, be offered - higher wages and that this will continue throughout their working lives.

Evidence to support this is provided by the university think-tank Million+, which disaggregated the accrued benefits from HE into higher incomes, more fulfilling jobs and less dependency on state benefits. It showed that the average 'earning premium' of an undergraduate degree is around 27 per cent compared to an individual leaving education with two 'A' levels or more; 
that the average net graduate premium reflecting 'the enhanced earnings associated with possession of a particular qualification' across an individual's working life is $£ 115,000$; and that an undergraduate degree increases the chances of staying in employment over one's entire working life by 3 per cent compared to those with 'A' levels (see Million+ 2013). In addition, Blundell et al. (2005) found the earning premium of HE was 48 per cent when compared to leaving school with no qualifications.

Naturally, not all the associated benefits are monetary. The Department for Education and Skills (2006, page 3) argues that 'graduates experience better health, are less likely to commit crime and are more likely to engage in civil society'. Evidence of non-pecuniary benefits is in line with the work of, among others, Walker (2010), who argues that education can expand the horizons of individuals to make choices regarding the type of society in which they want to live.

This being the case, there is a clear interface between the private (individual) benefits of HE and the more public good or benefit to economy and society as a whole. Once again Million+ provides evidence of increased returns to the Exchequer from additional tax revenues generated from more stable graduate employment and higher expected earnings: in blunt monetary terms, it estimates that the average net benefit to the Exchequer per student is $£ 94,000$ and that for the entire 2010-2012 UK-domiciled cohort the Exchequer's net benefit will be more than $£ 28$ billion during the cohort members' working lives.

Moreover, in line with the literature (see Brown 2013 and Thompson and Simmons 2013), Million+ is keen to stress HE's positive spillover effects on society, including the increased productivity of not only graduates but co-workers who learn by imitation. Quoting the work of Battu et al. (2003) and Metcalfe and Sloan (2007), it reports that untrained employees can increase their earnings by up to 9-12 per cent by working alongside employees boasting an additional year of education. Furthermore, Moretti (2004) reports that a 1 per cent increase in graduates within a city can increase wages therein by up to 1.9 per cent.

Setting to one side the issues of social mobility, which are well reviewed elsewhere (see Blandon 2002 and 2014, Gorard and Smith 2006 and Moore, Sanders and Higham 2013), there remain problems associated with the onset of mass HE. These include purpose, funding, usefulness and employment opportunities. All directly affect perceptions towards HE. As Professor Alison Wolf wrote in a 2002 article for the Times Education Supplement: 
Part of the problem is a deepening confusion over what our mass system is actually for. Junior ministers obediently trot out the line that "we need more young people to go to university because it is an economic necessity". But we passed that point long ago. Obviously all developed countries need university sectors: but within the Organisation for Economic Cooperation and Development there is no obvious relationship between levels of university attendance and wealth, or growth rates, or productivity.

It would therefore seem, contrary to the suggestion advanced by Mountford-Zimdars et al. (2013), that any explanation regarding graduate attitudes to expanding or widening access to HE must revolve around more than a simple desire to 'pull up the ladder'. The very nature of HE has changed dramatically, and its new role as a mass provider must inevitably influence student experiences and perceptions.

Externally, the interaction of graduates with the job market has altered significantly during the past few decades. Functionalist theory of industrialisation argues that HE fulfils the requirements of employers in terms of screening appropriate employees and providing a skilled and professional workforce (Goldthorpe 2007). Employers place ever-increasing emphasis on educational attainment as HE becomes more dominant and widespread, and this will gain stronger links with an individual's final destination in society as the importance of class origin begins to fade (see Brown 2013); yet a relative balancing of the various socio-economic groups cannot occur unless those from middle-class backgrounds are ready to fall to a lower socioeconomic status by not entering HE or by accepting lower-paid, less reputable employment.

There is little evidence of such fluidity within UK society: levels of absolute mobility have changed as mass HE has rolled out, but this has been due to an increase in the number of managerial and professional jobs over the past three decades (Brown 2013). It is this notion that might be at the heart of society's views concerning the rise of mass HE, in that HE may help an individual signal suitability for a certain type of job that in the past would not have required a university degree. Mass HE has shifted each level of employment upwards in terms of qualifications, but most socio-economic groups/individuals ultimately secure positions that they would have secured in the 1950s. HE becomes an increasingly redundant arbiter in this sense, as the higher classes use different means to signal to the employment market - or, as Brown (2013) states, there is a:

failing to recognize that what some achieve, all cannot: while everyone can do their best, not everyone can be the best... that individual achievements are not judged in isolation, but in a positional competition that typically privileges those from higher social class. (page 682)

Brown argues that this has led to 'social congestion': a degree has provided less and less in terms of strategic positioning as mass HE has rolled out, with too many degrees chasing too 
few degree-level jobs. Armed with more 'cultural capital', the most well placed in society have benefited as the worth of HE as a position good has dwindled (see Bourdieu 1997, Brown 2013 and 2006, West 2000 and Hirsch 1977). Such manoeuvering for positions in the job market means everyone has to fight harder to remain ahead of the pack. As Mayhew, Deer and Dua (2004, page 73) have argued: 'The system may have changed in such a way as to create more hoops through which [students] have to jump to reach the same destination as before.' Even the higher socio-economic classes have to work harder to stay in the same place, creating resentment and affecting graduate views of further expanding access to HE.

An increasing emphasis on 'cultural capital' goes hand-in-hand with rising competition to secure a place at a 'top' university. Work by Vignoles et al. (2008) found there was a wage premium for attending a 'better' HE institution of approximately 6 per cent per annum. Those from higher social classes have more ready access to universities that are considered better: often their family members might be alumni, but they also increase their worth by undertaking more extracurricular activities (see Roulin and Bangerter 2011). Overall, as Brown (2013) has noted, this trend has served principally to fuel yet further resentment:

Today, the sources of conflict as experienced by middle-class youth may not be expressed in class or gender terms (middle class versus working class; men versus women) but as a conflict around the institutions of education, employment and the job market. Conflict takes the form of a clash between expectations and institutional realities where a growing number of aspiring working-class and middle-class families are becoming 'institutionally disappointed'.

Brown alludes to this interaction between the internal (the actual education) and the external (the job market). Disappointment with the education experience emanates from pressures associated with the onset of mass HE, chief among them the transformation of HE institutions from boutique providers to sometimes-monolithic structures with a vast diversity of programmes. New departments, schools and structures are added; the role of the university alters and/or becomes unclear; difficulties in balancing research, teaching and business engagement arise. Importantly for the current study, the student body evolves and becomes more heterogeneous, leading to a loss of common culture, which affects both student expectations and satisfaction regarding overall HE experience (see Altbach 1999 and Daniel 1993). Bates and Kaye (2014) argue that expectations/satisfaction regarding quality of teaching, contact time, class size, the roles and expertise of lecturers, overall academic environment, fellow students and the ability to perform will all affect satisfaction, as will the final 'usefulness' or 'positioning' of a degree with regard to employability. 
Such concerns came into even sharper focus after the introduction in September 1998 of tuition fees of $£ 1,000$, which increased to a $£ 3,000$ top-up fee in 2004 and, following the recommendations of the Browne Review (2010), to an annual fee of up to $£ 9,000$ from September 2012. From 2000 to 2010, the time period examined in this study, the gradual rise in fees has prompted mounting accusations of a 'consumer culture' in HE, encouraging heightened expectations of both the HE experience and employability prospects - especially given a consistent media focus on the earning premium associated with degree holders (see Jones 2010 and Bates and Kaye 2014).

Recent work by Kandiko and Mawer (2013) offers evidence for a move towards a consumerist ethos, suggesting students across all years and locations want 'value for money' and that 'this was seen tangibly through sufficient contact hours and resources available and abstractly through institutions' investment in students, learning spaces and the educational community' (page 5). In addition, Kandiko and Mawer found students desire 'a personalised higher education experience, with small teaching sessions, [with] opportunities to meet other staff and students' (page 9).

With mass HE finding such ideals difficult to deliver, the evidence regarding student satisfaction with the HE experience is mixed. Universities have collected internal data on finalyear student satisfaction since the introduction of the National Student Survey (NSS) in 2005. By the year 2011-2012 final-year students rated their satisfaction with their HE experience higher than any other year since 2005 , with 85 per cent stating they were satisfied with their course (see HEFCE news archive 2012); in contrast, the Office of the Independent Adjudicator (OIA), which was established by the Higher Education Act 2004 (see http://www.oiahe.org.uk/about-us.aspx), reports that student complaints in England and Wales rose year on year from 2005 to 2012. The OIA received 542 complaints in 2005 and 2,012 in 2012; 2013 witnessed a slight drop, with 1,972 complaints received (see OIA Annual Report 2013, page 11). It is perhaps worth pointing out that NSS figures can contain inconsistencies and are also prey to the near-inevitable 'game-playing' by some - if not most - institutions.

In summary, then, the HE sector has changed enormously over the course of recent decades. In many ways it might be said to have changed beyond recognition. Students can no longer rely solely on a degree to secure a good job and are increasingly compelled to pursue extracurricular activities to distinguish themselves from the crowd. The HE student experience 
has evolved, becoming less boutique, more heterogeneous and more confused, with universities struggling to satisfy the demands of a new consumerist culture.

These dramatic shifts have inexorably impacted on perceptions regarding widening access to HE. Moreover, they will continue to do so. As Mountford-Zimdars et al. conceded in their closing comments, the suggestion that those who have already benefited from HE are now 'most inclined to pull the ladder up behind them' represents just 'one interpretation' of the situation (Mountford-Zimdars et al. 2013). With this in mind, we now turn to our methodology.

\section{Methodology}

Mountford-Zimdars et al. (2013) used a multinomial logit technique in undertaking their analysis of attitudes towards expanding HE. Their control variables - arguably chosen in an ad hoc manner - included gender, social class, whether children were currently living at home and whether any household members had benefited from private education. With respondents to the BSA survey being asked whether HE opportunities were 'just right' or should be increased or decreased, Mountford-Zimdars et al. correctly maintained that their approach provided a means of highlighting 'asymmetrical' patterns in attitudes. They concluded that graduates are merely selfish rational economic agents 'in favour of pulling up the ladder behind them and decreasing opportunities'.

We believe this 'interpretation' to be problematic. We question whether the techniques adopted are sufficient to eke out the intricacies that might underpin graduates' attitudes. Our view is that the explanation is more complex and that Mountford-Zimdars et al., by positing that negative attitudes to HE expansion might be due to graduates wanting to 'pull up the ladder', stand at odds with the 'social congestion' argument put forward by Brown (2013).

To test our viewpoint we investigate the robustness of Mountford-Zimdars et al.'s conclusion across four dimensions. We adapt and broaden the econometric methods; we address the ad hoc choice of control variables; we include a time dimension; and we disaggregate graduates according to how they value university education. Each of these adjustments is guided by the literature and discussed further below.

\section{Economic methodology}


The approach favoured by Mountford-Zimdars et al. (2013) does not fully utilise the responses to the question 'Opportunities for young people in Britain to go on to higher education - to a university or college - should be [increased/reduced/are about right]'. Rather than merely allowing for a tertiary response (increase, decrease or maintain the status quo), we use a fivepoint ordinal scale in which responses can range from 'higher education opportunities should be reduced a lot' to 'higher education opportunities should be increased a lot'. An ordinal data approach enables us to take advantage of both the intensity and the broader spectrum of responses and allows us to investigate whether graduates and non-graduates remain distinct in their attitudes to HE opportunities. We use an ordered probit rather than a multinomial logit approach.

\section{Specification}

In addition, there are potential problems with the control variables used by Mountford-Zimdars et al. (2013). For instance, the use of occupational structure (such as professional and intermediate working) is not robust, as social class and education will be correlated. To circumvent this issue we test whether changes to the specification have any impact on the graduate attitude findings. In particular, we introduce a 'supervisor' role variable, which controls for whether a respondent is employed as a supervisor of other employees, hypothetically allowing us to control for those that have a more positive attitude over the productivity-enhancement role of education in line with the work of Battu et al. (2003) Metcalfe and Sloan (2007), Moretti (2004) and Million+ (2013). It must be noted, however, that while our supervisor variable could also be related to social class, we found this not to be an issue as our dummy captures both high and low supervisory roles. For example, while 20.1 per cent in 2010 are found to be employed in higher management, 23.8 per cent are employed in technical occupations. Further, we ensured that we ran our empirical work with and without this variable. To this end, we propose:

\section{H1: Supervisors of other employees will support the expansion of $H E$.}

\section{Time dimension}

Mountford-Zimdars et al. (2013), in conducting their multinomial logit approach, use only 2010 BSA data. We see this as a missed opportunity, as there have been considerable changes in the structure of UK HE during the years covered by the BSA survey - not least the number of graduates obtaining a degree, which increased from 243,246 in 2000 to 278,380 in 2005 and 
330,720 in 2010 (Higher Education Statistics Agency 2013). We therefore analyse the years between 2000 and 2010 by pooling 2000, 2005 and 2010 data to investigate whether there is any evidence that the growth and change in the HE sector have shaped attitudes. We may expect, for example, to discern the onset of social congestion (Browne 2013) or to detect the influence of rising tuition fees.

H2: Graduate attitudes towards expanding HE will become increasingly negative during the period 2000-2010.

\section{Graduate characteristics}

Our central concern with the approach adopted by Mountford-Zimdars et al. (2013) is the oversimplified explanation of the finding that graduates were not in favour of further widening access to HE. Essentially, Mountford-Zimdars et al. (2013) provide no evidence that this is due to 'pulling up the ladder': rather, there is only a suggestion that this might be the case. As highlighted in our literature review, there is likely to be a multitude of complex and interacting reasons for graduates not supporting further expansion: following Brown (2013), we broadly disaggregate these into internal institutional reasons and external job market or social congestion reasons.

To investigate these issues further and allow us to provide more evidence to underpin the literature, we separate negative attitudes over the availability of HE opportunities into three types. This disaggregation is guided directly by recourse to the literature, enabling us to investigate the nature of attitudes in more detail.

'Graduate Type 1' are the 'institutionally disappointed' (Brown 2013). These report finding their university experience 'not worth the time and money'. This disaggregation allows us to test directly for institutional issues affecting graduates' opinions, uniquely examining the assertions of Altbach (1999), Daniel (1993) and Bates and Kaye (2014) that student experience will affect opinion and the desire to see further HE expansion.

'Graduate Type 2' are the wary. These report that a university degree no longer 'guarantees a good job'. This disaggregation is designed to help provide evidence for Brown's (2013) social congestion theory. 
'Graduate Type 3' are those graduates who do not fall into either of the above categories. This disaggregation is used as the reference category in our models.

This leads us to two additional hypotheses:

H3: Graduates disappointed with their personal experience are more likely to have negative attitudes regarding expanding $H E$.

H4: Graduates believing that a degree no longer guarantees a job are more likely to have negative attitudes regarding expanding $H E$.

\section{Results}

Our results are presented in Table 1. In order to interpret them it should be noted that a positive parameter implies that this characteristic leads to a switch away from 'opportunities should be reduced a lot' to 'opportunities should be increased a lot'; in contrast, if the parameter is negative then this leads to the respondent switching in the alternative direction, with a greater probability of perceiving 'opportunities should be reduced a lot'.

Given the importance of graduate perceptions of the value of a university education, we also provide marginal effect estimates. Setting all other parameters according to mean characteristics of our sample, these show how belonging to either Graduate Type 1 or Graduate Type 2 influences the probability of being in each category of our dependent variable.

\section{[Table 1 here]}

Our 'time dimension' results in column 2 indicate some support for the findings in MountfordZimdars et al. (2013). Male respondents, for example, are significantly less likely than women to support expanding HE opportunities.

This is an interesting finding, since, as discussed above, women now make up approximately 55 per cent of those enrolling for a first degree. Research also shows they academically outperform men in terms of overall degree classification (Department for Business, Innovation and Skills 2012). Yet when it comes to employment opportunities they continue to lag behind, with recent research reporting that in 2012-2013 36 per cent of female graduates ended up in jobs not requiring a degree (compared to 30 per cent of men) (see Black 2015). This is evidence that women, despite being more likely to suffer if female graduates increase and the current 
job market continues to favour male graduates, may be more accepting of expansion and less concerned with the many issues associated with mass HE.

Also in line with Mountford-Zimdars et al. (2013), we find that those who have had a private education are statistically significantly more likely to want opportunities to be reduced than those who have attended state schools. We also find that Labour and Liberal Democrat voters are more likely than Conservative voters to favour HE expansion - a finding that is in slight contrast to Mountford-Zimdars et al. (2013), who do not distinguish between Conservatives and Liberal Democrats in their attitudes towards expansion.

Our adaptations to the empirical approach indicate robustness problems in Mountford-Zimdars et al. (2013): consider, for example, our introduction of a 'supervisor' as a proxy to control for those who may have a more positive attitude regarding the productivity-enhancement role of education. This improvement is made not only because using occupational structure such as professional or intermediate working is likely to be related to education levels but to add further evidence to the work of Battu et al. (2003), Metcalfe and Sloan (2007), Moretti (2004) and Million+ (2013), which shows that graduates and those who work alongside them deliver tangible improvements to productivity.

As can be seen in Table 1, the supervisor variable is positive. This indicates that those in supervisory roles are more likely to report wanting an expansion in HE than those in nonsupervisory roles. We therefore find support for hypothesis $\mathrm{H} 1$ and provide some tentative qualitative evidence to corroborate the quantitative work of researchers in this area such as Moretti (2004).

Perhaps the most critical findings relate to how attitudes towards expanding HE have changed over time. We report that all respondents in 2005 and 2010, irrespective of their level of education, are more likely to support significant reductions in HE opportunities. These results make it doubtful that Mountford-Zimdars et al. (2013) are picking up 'pulling up the ladder' effects. Given that these changes coincide with a significant increase in graduate numbers, this provides more evidence of problems associated with the continued growth of mass HE - for instance, internal disaffection, the rise in tuition fees or Brown's (2013) notion of social congestion. In line with this evidence, we accept hypothesis $\mathrm{H} 2$.

Turning to the 'graduate dimension' results in Table 1, we find further evidence that the conclusions of Mountford-Zimdars et al. (2013) are not robust. In this ordered probit our 
reference category is graduates who neither report that university 'is not worth the time and effort' nor report that a degree 'doesn't guarantee a good job': we find that, compared to nongraduates, these graduates are not significantly more likely to want to reduce opportunities (as the coefficients are insignificant). This leads us to reject the 'pulling up the ladder' hypothesis of Mountford-Zimdars et al. (2013).

Despite this, we find evidence that our graduate types are more likely to want to reduce HE opportunities to the young. This provides evidence that the student experience and the ability to obtain a job affect graduate attitudes towards further expansion. Our results therefore support the ideas forwarded by Altbach (1999), Daniel (1993) and Bates and Kaye (2014), who argue that student experience will affect graduate desire to see further expansion. In addition, our results provide evidence for Brown's (2013) notion of social congestion and the ability of graduates to find employment; and for the work of Mayhew, Deer and Dua (2004), who argue that the need for higher socio-economic classes to work harder to gain employment creates resentment and also affects graduate views regarding the further expansion of HE.

\section{Conclusions}

This paper was inspired by the recent work of Mountford-Zimdars et al. (2013) and the changing UK HE landscape over recent decades, during which time there seems to have emerged a consensus that both expanding and widening access to $\mathrm{HE}$ is positive for all in society and therefore should be supported by all.

As we have seen, expansion has certainly made HE more available to women. In absolute terms, more individuals from the lower social classes have also entered HE. In addition, there is much evidence to support the benefits of obtaining a first degree - both to the individual (in terms of better chances of employment, higher remuneration and more general engagement with society) and to society as a whole (in terms of the wider benefits that graduates bring to the work environment, the Exchequer and the economy's productive capacity).

With such obvious benefits and a formed consensus, the work of Gorard (2013) and, more interestingly, the results obtained by Mountford-Zimdars et al. (2013) appeared incongruous. In light of this, we took the latter's work as a starting point from which to build a more robust approach and to question the inference that graduates want to 'pull up the ladder'. 
Further investigation of the literature produced a more complex picture in which the move to mass HE has introduced problems as well as benefits. These problems present themselves both internally and externally - that is, within institutions and in the market for job opportunities. Our results have provided further evidence of a fracturing in the consensus of expanding $\mathrm{HE}$ to the young which has become increasingly embedded over the decade 2000-2010. As well as building on the methods of Mountford-Zimdars et al. (2013), our findings offer some statistical evidence to support the work of Brown (2013) and the notion of social congestion and the work of Bates and Kaye (2014) regarding internal institutional experience and levels of student satisfaction.

Overall, we find that Conservative-supporting, privately educated males are more likely to favour a reduction in opportunities. In addition, by adding a 'supervisory' variable, we provide support for the notion that those in supervisory roles are more likely to report wanting an expansion in HE than those in non-supervisory roles.

Most interestingly, we find that all respondents in 2005 and 2010, at all levels of education, are more likely to support significant reductions in HE opportunities. We therefore conclude that it is doubtful that Mountford-Zimdars et al. (2013) are picking up 'pulling up the ladder' effects: instead we interpret this result as evidence of the effect of internal disaffection, the rise in tuition fees or, as posited by Brown (2013), the notion of social congestion. Consequently, we encourage further research that uses a mixed-methods approach to examine attitudes and shed further light on this important and complex subject.

Mountford-Zimdars et al. inferred that graduates, having benefited from a university education, may want to 'pull up the ladder', presumably to selfishly prevent others from emulating their success; by contrast, our findings indicate that graduates, having found a university education less beneficial than they might have expected, may want to selflessly spare others a climb that might not prove as worthwhile as they imagine.

One final note on our interpretation and a nudge towards encouraging further research in this area. The focus of our paper has been on graduates' attitudes towards expanding HE which is a process. However, the support we find for the theory of social congestion could actually be compatible with the principle that HE expansion is a fixed, marketed state. That is, the views of students could be interpreted as a rejection of what might otherwise be taken to be a social democratic dynamic process aimed at opening up and 'democratising' HE. This view also sits 
within our social congestion interpretation. Given the limitations of our methodology, disentangling between the two interpretations of graduates either rejecting democratisation or rejecting overcrowding (or both), is out with the scope of the current paper. This is down to the fact that we cannot empirically examine this issue due to the BSA altering its formulation through the years. Specifically - responses are given to different questions across the years in the BSA and our covariates do not allow for further analysis. As such we leave the disentangling of this problem for further research using alternate methodologies.

Either way, the assumed and accepted consensus over the widening of access to HE appears increasingly fragile, if not fatally mistaken. We believe it is vital that the clearest possible picture is developed if government policy is to accurately reflect reality.

\section{References}

Altbach, P.G. (1999) 'The Logic of Mass Higher Education', Tertiary Education and Management. Vol. 5. Issue 2. Pg. 105-124.

Bates, E.A. and Kaye, L.K (2014) "'I'd be expecting caviar in lectures": the impact of the new fee regime on undergraduate students' expectations of Higher Education. Higher Education. Vol. 67. pg. 655-673.

Battu, H. Belfield, C.R. and Sloane, P. J. (2003). 'Human Capital Spillovers within the Workplace: Evidence for Great Britain', Oxford Bulletin of Economics and Statistics, Vol. 65(5). pg.575-594.

Baum, S. and McPherson, M. (2011, January 18). 'Is education a public or a private good? The Chronicle of Higher Education' Retrieved from http://chronicle.com/blogs/innovations/iseducation-a-public-good-or-a-private-good/28329

Black, J. (2015) 'Study reveals careers 'gender gap' for university graduates' The Careers Service. University of Oxford Press Release.

Blanden, J. Goodman, A. Gregg, P. and Machin, S. (2002) 'Changes in Intergenerational Mobility in Britain', Centre for the Economics of Education. London School of Economics and Political Science. June.

Blanden, J. and Macmillan, L. (2014) 'Education and Intergenerational Mobility: Help or Hindrance?', Centre for Analysis of Social Exclusion. London School of Economics. CASE/179. January

Blundell, R. Dearden, L. and Sianesi, B. (2005) 'Measuring the Returns to Education', in S. Machin and A. Vignoles (eds.) What's the Good of Education?, Princeton University Press, Princeton, US.

Bolton, P. (2010) 'Higher Education and Social Class', Standard Note. Library of the House of Commons. SN/SG/620. 
Bolton, P. (2012) 'Education: Historical Statistics', Standard Note. Library of the House of Commons. SN/SG/4252.

Bourdieu, P. (1997) 'The Forms of Capital', in Halsey A.H. Lauder H. Brown P. and Stuart Wells, A. (eds) Education, Culture, Economy, Society. Oxford: Oxford University Press.

Brown, P. (2006) 'The Opportunity Trap', (revised and abridged) in Lauder, H. and Brown, P. and Dillabough, J. A. (eds) Education, Globalization and Social Change. Oxford: Oxford University Press.

Brown, P. (2013) 'Education, opportunity and the prospects for social mobility', British Journal of Sociology of Education, Vol. 34. Nos. 5-6. pg. 678-700.

Browne Report. 2010. Securing a Sustainable Future for Higher Education - an Independent Review of Higher Education Funding and Student Finance. London.

Cabinet Office (2011) Opening doors, breaking barriers: a strategy for social mobility. Cabinet Office and Deputy Prime Minister's Office. London. https://www.gov.uk/government/publications/opening-doors-breaking-barriers-a-strategy-forsocial-mobility

Calhoun, C. (2006) 'The University and the Public Good', Thesis Eleven 84 (1):7-43.

Chesters, J. and Watson, L. (2013) 'Returns to education for those returning to education: evidence from Australia', Studies in Higher Education. Vol. 39. No. 9. pg. 1634-1648.

Dearing Report (1997) National Committee of Inquiry into Higher Education. Department for Business, Information and Skills. 2012. Statistical First Release, Academic Year 2010/11 (Provisional). London: BIS.

Department for Business Innovation \& Skills (2014) Participation Rates in Higher Education: Academic Years 2006/2007 - 2012/2013. National Statistics. London.

Department for Education and Skills (2006) Widening Participation in Higher Education. Sheffield.

East, L. Stokes, R and Walker, M. (2014) 'Universities, the public good and professional education in the UK', Studies in Higher Education. Vol. 39. No. 9. pg. 1617-1633.

Goldthorpe, J. H. (2007) On Sociology: Volume Two - Illustrations and Retrospect. 2nd ed. Stanford: Stanford University Press.

Goldthorpe, J., and A. McKnight. 2006. "The Economic Basis of Social Class.” In Mobility and Inequality: Frontiers of Research from Sociology and Economics, edited by S. Morgan, D. B. Grusky and G. S. Fields. Stanford: Stanford University Press.

Goldthorpe, J. H., and C. Mills. 2008. "Trends in Intergenerational Class Mobility in Modern Britain: Evidence from National Surveys." National Institute Economic Review 205: 83-100.

Gorard, S. (2013) 'The limitations of widening participation'. Adults Learning. Vol. 25: 20-21. 
Gorard, S. and Smith, E. May, H. Thomas, L. Adnett, N. and Slack, K. (2006) 'Review of widening participation research: addressing the barriers to participation in higher education. A report to HEFCE'. The University of York, Higher Education Academy and Institute for Access Studies.

Higher Education Funding Council for England (HEFCE) (2012) 'Highest ever satisfaction rates in 2012 student survey', http://www.hefce.ac.uk/news/newsarchive/2012/news75522.html

Higher Education Statistics Agency (2013) Destination of Leavers from Higher Education. https://www.hesa.ac.uk/pubs/index.php?option=com_pubs\&task=show_pub_detail\&pubid=1 $708 \&$ Itemid $=$

Hirsch, F. (1977) Social Limits to Growth. London: Routledge and Kegan Paul.

Jones, G. (2010) 'Managing student expectations: The impact of top-up tuition fees', Perspectives. Vol. 14. No. 2. pg 44-48.

Kandiko, C. B. \& Mawer, M. (2013) Student Expectations and Perceptions of Higher Education: Executive Summary. London: King's Learning Institute.

Lindley, J., and S. Machin. (2012) 'The Quest for More and More Education: Implications for Social Mobility'' Fiscal Studies. Vol. 33. No. 2. pg. 265-286.

Mayhew, K. Deer, C. and Dua, M. (2004) 'The move to mass higher education in the UK: many questions and some answers', Oxford Review of Education. Vol. 30. No.1. March.

Metcalfe, R. and Sloane, P. J. (2007) Human Capital Spillovers and Economic Performance in the Workplace in 2004: Some British Evidence. Institute for the Study of Labor (IZA).

Million+ (2013) What's the value of a UK degree? Million+ and London Economics. London.

Moore, J. Sanders, J. and Higham, L. (2013) Literature review of research into widening participation to higher education, Report to HEFCE and OFFA by ARC Network. August.

Mountford-Zimdars, A. Jones, S. Sullivan, A. and Heath, A. (2013) 'Framing higher education: questions and responses in the British Social Attitudes survey, 1983-2010', British Journal of Sociology of Education. Vol. 34. Nos. 5-6. pg. 792-811.

Moretti, E. (2004) 'Estimating the social return to higher education: evidence from longitudinal and repeated cross-sectional data', Journal of Econometrics, Vol. 121(1-2), p.175-212.

National Centre for Social Research (2010) British Social Attitudes 2010: Face to face questionnaire. London: National Centre for Social Research available for download at: http://www.natcen.ac.uk/media/778212/bsa28-questionnaire.pdf.

National Equality Panel. 2010. An Anatomy of Economic Inequality in the UK: Report of the National Equality Panel. London: Government Equalities Office.

Office of the Independent Adjudicator (2013) Annual Report. Reading. 
Robbins Report (1963) Higher Education, Report of the Committee Appointed by the Prime Minister under the Chairmanship of Lord Robbins. London: Her Majesty's Stationery Office.

Roulin, N. and Bangerter, A. (2011) 'Students' use of extra-curricular activities for positional advantage in competitive job markets', Journal of Education and Work. Vol. 26, No. 1.pg 2147.

Teaching \& Learning Research Programme (2008) 'Widening participation in higher education: A Commentary by the Teaching and Learning Research Programme'. TLRP Institute of Education. University of London.

Thompson, R. and Simmons, R. (2013) 'Social mobility and post-compulsory education: revisiting Boudon's model of social opportunity. 'British Journal of Sociology of Education, 34 (5-6), pp. 744-765

Universities UK (2012) Patterns and trends in UK Higher Education. London

Vignoles, A. et al (2008). Widening Participation in Higher Education: A Quantitative Analysis: Full Research Report

Walker, M. (2010) 'A human development and capabilities 'prospective analysis' of global higher education policy’, Journal of Education Policy. Vol. 25. No. 4. pg. 485-501.

West, J. (2000) 'Higher Education and Employment: opportunities and limitations in the formation of skills in a mass higher education system', Journal of Vocational Education and Training. Vol. 52. No. 4. pg. 573-588.

Wolf, A. (2002) 'We're still skipping (working) class'. The Times Higher Educational Supplement, Vol. 24, May, 18-19.

World Bank (1994) Higher Education: The Lessons of Experience. Washington, DC: The World Bank. 
Table 1: An ordered probit analysis into attitudes towards expanding $\mathrm{HE}$ opportunities for young people

\begin{tabular}{|c|c|c|}
\hline Variable & Time Dimension & $\begin{array}{c}\text { Graduate Dimension } \\
\text { (2010 data only) }\end{array}$ \\
\hline Constant & $2.203^{*}$ & $1.520^{*}$ \\
\hline Male & $-0.0927^{*}$ & -0.0291 \\
\hline Supervises Workers & $0.1651 * * *$ & -0.0130 \\
\hline Received Private Education & $-0.3381^{*}$ & $-0.4609 *$ \\
\hline Has Children & $0.2308^{*}$ & $0.2604^{*}$ \\
\hline Labour voter & $0.2839^{*}$ & $0.2802 *$ \\
\hline Liberal Democrat voter & $0.1711^{*}$ & $0.1795 * * *$ \\
\hline \multicolumn{3}{|l|}{ Reference category: 2000 respondent } \\
\hline Graduate (2005 respondent) & $-0.5354 *$ & \\
\hline Graduate (2010 respondent) & $-0.7411^{*}$ & \\
\hline Below Graduate (2005 respondent) & $-0.3661 *$ & \\
\hline Below Graduate (2010 respondent) & $-0.2934^{*}$ & \\
\hline Low Qualifications (2005 respondent) & $-0.2381 *$ & \\
\hline Low Qualifications (2010 respondent) & $-0.3539 *$ & \\
\hline \multicolumn{3}{|l|}{ Reference category: Graduate Type 3} \\
\hline Low Qualifications & & -0.1023 \\
\hline Further Qualifications & & 0.0632 \\
\hline Graduate Type 1 & & $-0.4767 *$ \\
\hline Graduate Type 2 & & $-0.4541 *$ \\
\hline $\operatorname{Mu}(1)$ & 0.8721 & 0.6414 \\
\hline $\operatorname{Mu}(2)$ & 2.353 & 1.965 \\
\hline $\operatorname{Mu}(3)$ & 3.006 & 2.641 \\
\hline Log-L & -5191.91 & -1475.12 \\
\hline $\log -\mathrm{L}(0)$ & -5356.63 & -1511.96 \\
\hline Number of observations & 4064 & 1081 \\
\hline McFadden Pseudo $\mathbf{R}^{2}$ & 0.031 & 0.0244 \\
\hline
\end{tabular}

Notes: * significant at 1\%; ** significant at 5\%; *** significant at 10\%; Marginal effects for Graduate Types are as follows:

\begin{tabular}{|c|c|c|c|c|c|}
\hline & $\mathrm{Y}=0$ & $\mathrm{Y}=1$ & $\mathrm{Y}=2$ & $\mathrm{Y}=3$ & $\mathrm{Y}=4$ \\
\hline Graduate Type 1 & 0.0765 & 0.0702 & 0.0103 & -0.0733 & -0.0837 \\
\hline Graduate Type 2 & 0.0704 & 0.0669 & 0.0145 & -0.0696 & -0.0823 \\
\hline
\end{tabular}

